\title{
MAIS DO QUE RESISTÊNCIA, AVANÇO: DESDE O BOICOTE DE MINHA SENHORA DE MIM À SUA CANONIZAÇÃO
}

\author{
Ana Bárbara Pedrosa* \\ Universidade Federal de Santa Catarina
}

Resumo: Iremos neste artigo analisar de que forma Minha Senhora de Mim (1971), de Maria Teresa Horta, atentou o regime ditatorial que foi o seu zeitgeist, partindo da forma como usou a literatura canónica e a tradição literária para desafiar um status quo, trazendo para a literatura portuguesa um novo modelo de relações entre os sexos, contrastante com as políticas impostas pelo Estado Novo, constitucionalmente consagradas, reclamando para as mulheres o direito ao prazer sexual e a um lugar na sociedade que não se limitasse ao de coadjuvante. $\mathrm{O}$ desafio à tradição literária merecerá alguma atenção, na medida em que é feito através da subversão do conteúdo das cantigas de amigo medievais. Num segundo ponto, analisaremos não só o contexto da produção da obra literária, mas também a ação consequente da PIDE. Finalmente, iremos analisar o papel da polícia política no boicote desta obra e da carreira literária da autora, tentando entender se foi aqui bem sucedida, assim como o papel que a obra desempenha hoje no cânone literário português.

Palavras-chave: Maria Teresa Horta. Poesia. Ditadura. Censura. Cânone.

\section{O lugar de Maria Teresa Horta na literatura portuguesa}

O nome de Maria Teresa Horta é quase indissociável da literatura portuguesa produzida a partir de meados do século XX. Nascida em 1937, a autora conta já com trinta e cinco obras publicadas, entre ficção e poesia, e alguns prémios literários arrecadados, como o Prémio Máximo de Literatura (2010) ou o Prémio D. Dinis (2011), tendo o primeiro sido instituído pela revista Máxima, dedicado à literatura portuguesa produzida por mulheres, e o segundo pela Fundação Casa de Mateus.

A sua vida pública, contudo, não se fez somente por via da estética literária. Aliás, esta foi, não raras vezes, usada como uma forma de veicular posições políticas, e a autora tem sido conotada com movimentos sociais feministas, seja pela escrita de obras como Novas

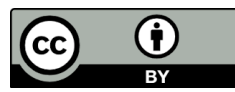

Esta obra está licenciada sob uma Creative Commons - Atribuição 4.0

\footnotetext{
Doutora em Ciências Humanas pela Universidade Federal de Santa Catarina. E-mail: anabarbarapedrosa@gmail.com.
} 
Cartas Portuguesas (1972) ${ }^{1}$, que escreveu com Maria Isabel de Barreno e Maria Velho da Costa, como pela pertença ao Movimento Feminista de Portugal ou mesmo pela chefia da redação da revista Mulheres, um projecto seu, também ele dito feminista.

A actividade da autora iniciou-se muito cedo e cabe lembrar que, à época do começo da sua ação política e literária, Portugal vivia sob o domínio da ditadura salazarista, que não só confinava as mulheres ao espaço doméstico ${ }^{2}$, impedindo-lhes o acesso à produção simbólica, como agia directamente sobre as obras que considerava atentatórias da moral do regime, proibindo-as e, não raras vezes, prendendo ou processando autores. Os problemas de Maria Teresa Horta com a PIDE, polícia política do regime, começaram quando esta tinha dezoito anos, sendo já a primeira mulher a dirigir um clube português, o Cine-clube $\mathrm{ABC}$, em Lisboa. O cargo ocupado valeu-lhe um comentário depreciativo de César Moreira Baptista, censor literário e subsecretário de Estado da Presidência do Conselho, que viria a tentar boicotar a carreira literária de Horta: "Pobre país este, que já tem mulheres dirigentes de cineclubes" (NUNES, 2007, p. 7). Moreira Baptista estaria, em 1971, ao leme do processo dirigido a Snu Abecassis, que dirigia a colecção "Cadernos de Poesia", das Publicações Dom Quixote, em que Minha Senhora de Mim foi publicada. O censor, para além de acusar a editora de ofender a moral tradicional do país, ameaçou-a com o encerramento da editora no caso de voltar a publicar textos de Horta.

As publicações da autora foram inicialmente feitas através de Suplementos Literários, no Diário de Lisboa (aqui foi jornalista, antes de sê-lo no jornal A Capital), e consistiam em poemas. A sua produção literária começou na década de sessenta, uma época

\footnotetext{
${ }^{1}$ Projecto literário iniciado em 1971, a obra viria a público em Maio do ano seguinte, tendo de imediato sido vilipendiada pelo regime salazarista, que, para deslegitimá-la, a considerou pornográfica. No decorrer da obra, há uma clara intenção de denúncia, ao serem descritos casos de subalternidade de mulheres, mostrando-se a relação de poder que existia entre os sexos, transversal às classes, e mostrando-se, assim, que estas derivavam de condições políticas e não naturais. Desta forma, a obra contrariava o que apregoava o Estado Novo: que os géneros tinham caraterísticas biológicas e que estas deviam definir o lugar social de cada um. O papel transgressor da obra é geralmente admitido: a série de afrontas ao status quo imbuía-se já de uma nova proposta política e social, que passaria, através da expressão do zeitgeist de concepção, pela conquista de direitos cívicos, da liberdade de expressão e do acesso à produção simbólica. O exercício estético, assim, funcionou como ferramenta política.

2 Em Abril de 1933, entrou em vigor a Constituição Política que consagrou o Estado Novo. Este era um documento de grande conteúdo ideológico: opondo-se à Constituição firmada em 1911, tinha o objetivo de subordinar a ação do Estado a uma série de posições políticas, através das quais se imporia o nacionalismo, o apostolado em nome do catolicismo, a afirmação do império português e a família como célula estrutural da sociedade portuguesa. Tentando enquadrar o país numa visão cristã do mundo, o salazarismo fazia do mote "Deus, Pátria e Família" um dos grandes eixos controladores da ação política e social, querendo nortear a moral do país, mostrar a pátria como versão colectiva do individual e fazer da família uma célula de estruturação da sociedade. Neste quadro, a cultura dominante impunha um paradigma que afastava as mulheres do acesso à produção simbólica. Pelo contrário, a estas devia estar destinada a vida doméstica, enquanto a vida pública - e política, portanto - seria o espaço de ação dos homens. Esta divisão encontrava expressão na própria Constituição, já que era esta que afirmava garantir a igualdade perante a lei "salvo no que se relaciona com o sexo, considerando a diferença de natureza da mulher e o bem da família".
}

Anu. Lit., Florianópolis, v. 22, n. 1, p. 116-127, 2017. ISSNe 2175-7917 
em que se reflectia na literatura a procura pelo entendimento do lugar dos seres humanos no mundo e a busca pela liberdade, contrastando isto com os grilhões ditatoriais que tentavam decepá-la, e nessa década publicou nove obras. A primeira, Espelho inicial (1960), é já uma obra transgressora, já que desconstrói a identidade feminina tal como era aceite e imposta pelo status quo de então ${ }^{3}$. A obra da autora, extensa, que se divide entre poesia e ficção, pauta-se em grande parte pelas temáticas do erotismo e do engajamento político, sendo que ambas se mesclam para que Horta faça uma nova proposta do mundo. É que, com a junção de ambas, a sua obra literária é activa na luta contra o patriarcado, reconhecendo às mulheres o direito à sexualidade e à participação política. Iremos, neste artigo, explicar de que forma isto se verificou na obra Minha Senhora de Mim, publicada em 1971, referindo-nos ainda à recepção que essa obra teve (e que mostra também o carácter político do texto).

\section{Minha Senhora de Mim (1971)}

A intertextualidade é uma das características da obra de Maria Teresa Horta que não podem passar despercebidas. Se Educação Sentimental (1975) dialoga com a quase homónima obra de Flaubert L'Éducation Sentimentale (1869), também não podemos esquecer-nos do diálogo que Novas Cartas Portuguesas estabelece com obras das três autoras, Maina Mendes (1969), de Maria Velho da Costa, Ambas as mãos sobre o corpo, de Maria Teresa Horta (1970), Outros legítimos superiores (1970), de Maria Isabel Barreno, e com Lettres Portugaises, romance publicado por Claude Barbin em 1669. Minha Senhora de Mim, por sua vez, viria a encontrar eco em Minha Senhora de Quê, de Ana Luísa Amaral, publicada pela Quetzal Editores em 1990. Para além disto, a obra de Horta dialoga com as cantigas de amigo medievais. Assim, nos cinquenta e nove poemas que compõem Minha Senhora de Mim, é usada a forma poética destas últimas, sendo a literatura canónica - e, concomitantemente, a tradição literária - usada de forma a desafiar um status quo que existe aqui na forma do pensamento patriarcal.

O desafio à tradição literária merecerá alguma atenção, na medida em que é feito através da subversão do conteúdo das cantigas de amigo medievais. Afinal, nestas, a voz poética era feminina, ainda que os poemas fossem escritos por homens, e incidia quase sempre no sofrimento por amor, devido à ausência do "amigo" e ficando o sujeito poético mulher, reitere-se - emocionalmente dependente de um homem. Em Minha Senhora de Mim,

\footnotetext{
3 Afastando as mulheres do centro das decisões políticas e vedando-lhes o acesso ao trabalho e a salários, empurrando-as para a dependência económica dos homens, o Estado Novo perspectivava as mulheres enquanto esposas, fadas do lar e mães.
} 
contudo, a forma poética é usada ao serviço de outra concepção do mundo: aquela em que a mulher, centro da narrativa dos poemas e autora real dos poemas, é ainda centro do desejo sexual, sendo ainda imperativa, comandando a relação heterossexual, rejeitando ser dominada e dependente. Aliás, o sujeito poético da obra não só rejeita a submissão como submete.

Ana Maria Domingues de Oliveira reflecte precisamente sobre a influência trovadoresca na obra, considerando que a obra de Horta propõe uma releitura do Trovadorismo português: ao usar as cantigas de amigo através de uma perspectiva crítica e paródica, a autora atingiria, também de forma crítica, a identidade nacional, graças à sobreposição dos conceitos de identidade literária e identidade nacional (OLIVEIRA, 2009, p. 4-5). Ou seja, alterando a relação entre os sexos defendida e propagada pelo Estado Novo (recorde-se a já referida Constituição que expressava o modelo dessa relação), sugeria-se um novo modelo de estrutura social - instalando-o, por romper com o obrigatório -, desafiandose, desta forma, a moral instituída constitucional e socialmente. Assim, a moral tradicional do salazarismo era afrontada pela forma literária: ao pôr-se as mulheres no epicentro de uma narrativa em que elas assumiam a sua independência e a sua liberdade, criava-se um mundo em que estas eram donas de si e não se confinavam ao quadro de dominação em que o Estado Novo as integrava. A prática política do regime, que resultava em dominação patriarcal, era rejeitada por uma escritora que, através da produção simbólica, geralmente vedada às mulheres, reclamava para si e para as outras um lugar social e o ocupava sem esperar permissão. No mesmo movimento, Minha Senhora de Mim extrapola o quadro da sociedade portuguesa, ao mostrar o patriarcado como pano de fundo da cultura ocidental, já que traz para o seu tempo a Idade Média, através da tradição literária.

Nos poemas que compõem esta obra, se a novidade de se dar voz à sexualidade das mulheres não pode passar despercebida, mais de destacar será ainda o tom imperativo que é usado nos poemas, já que é através deste que a mulher, sujeito poético, comanda a ação, dizendo ainda ao homem o que deve fazer de forma a agradar-lhe. Ademais, é dela que parte a iniciativa e é por ela que a relação sexual é descrita como busca pelo prazer, esvaziando-se do seu carácter procriador ou até, uma vez que reclama o prazer para a mulher, de uma relação de poder do homem sobre a mulher. O zeitgest em que a obra foi concebida não será de somenos: à época, Portugal estava mantido sob o véu da moral católica e a mulher, que devia responder na figura de esposa, mãe e fada do lar, estava social e simbolicamente afastada do prazer sexual, por motivos de moral imposta ou religiosos, ainda que o prazer masculino fosse permitido ou socialmente aceite. A mulher, uma vez que a vida pública se regia pela ideia de 
que ela devia reger-se por um espírito de sacrifício, também verificado no sexo, devia estar subjugada. Foi contra esta ideia, contra esta naturalização da opressão que era tão benéfica à manutenção do Estado Novo, contra a naturalização da opressão que mantinha as mulheres à margem da vida pública e fazia delas coadjuvantes na vida privada, que Maria Teresa Horta, ultrapassando já a barreira que a confinava ao espaço doméstico, reclamou para si o acesso à produção simbólica, criando uma voz de comando e feminina. Esta é uma voz que ordena e orienta e, com ela, a procura pelo prazer sexual é clara, indisfarçável, indisfarçada.

O poema "O meu desejo", preciso, incisivo, trará essa buscar de forma clara. Reparese:

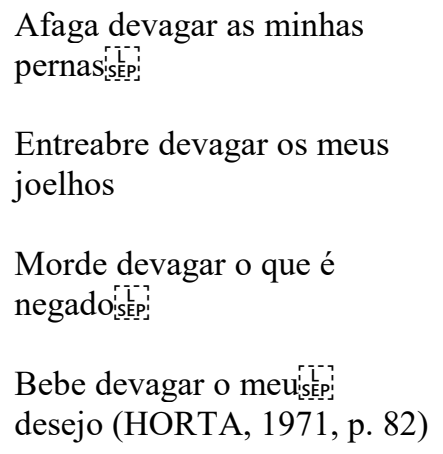

Com isto, a autora rompe com a tradição literária verificada nas cantigas de amigo, que, colocando as mulheres no epicentro de uma narrativa, a deixavam sempre numa relação de dependência. Horta subverte isto, trazendo para a voz poética - feminina - a utilização do modo imperativo, usada em prol de uma relações de forças estabelecida, desta vez, em prol da mulher. Para além disto, a ação que descreve é explícita, rejeitando-se o papel presumivelmente assexuado das mulheres. O mesmo acontece no "Poema ao desejo", que se inicia com a seguinte estrofe: "Empurra a tua espada/ no meu ventre/ enterra-a devagar até ao cimo" (HORTA, 1971, p. 84). Como o poema anterior, também este é escrito sob o modo imperativo. A "espada" referida no primeiro verso, como símbolo do homem, será ainda uma metáfora recorrente da poesia de Horta, e concretamente em Minha Senhora de Mim, e podemos vê-lo no poema que precisamente se intitula "Minha espada". A transgressão iniciase já no título do poema, através do pronome usado, que confere a posse ao sujeito poético, mulher: o sujeito feminino, assumindo a posse, domina e manuseia, recusando a subjugação. Contudo, esta ideia irá contrastar com outra apresentada no poema, que é a imagem da terra "Solidão de terra ferida/ feita/ planta ou jornada" (HORTA, 1971, p. 24), que representa uma imagem de submissão, uma vez que espera fertilização, e cujos abandono e solidão são o que motiva o sofrimento "ignorada e perdida" (HORTA, 1971, p. 24). Para mais, na última 
estrofe "Vazio que habito esquecida/ Com meu ventre e sua espada" (HORTA, 1971, p. 24), gira-se em torno do símbolo fálico e a mulher passa por objeto submisso, por "repouso da espada".

O poema "As nossas madrugadas", por sua vez, paraleliza-se com textos prosaicos de Novas Cartas Portuguesas, especialmente o "Texto sobre a solidão", uma curta narrativa em que a relação sexual é utilizada como mera manobra de subjugação. Afinal, o poema refere-se a um domínio masculino, físico, que termina em violação, numa ação que traz à memória Bourdieu, que interpreta a relação sexual como uma relação sexual de dominação, construída através do princípio de divisão entre o masculino, ativo, e o feminino, passivo. Este princípio dirigirá o desejo masculino como desejo de posse e o feminino como desejo de dominação masculina, aliando-se aqui a dominação e a subordinação erotizadas, passando mesmo a haver um reconhecimento erotizado da dominação (BOURDIEU, 2012, p. 31). Assim, no texto de Novas Cartas Portuguesas, o gosto do homem na subjugação feminina prova o desejo de posse e a necessidade de assumpção de poder. Desta forma, o poder assume a figura da subjugação física da mulher. O mesmo se passará no poema referido, em cuja primeira estrofe a mulher é acordada para a satisfação do homem: "Desperta-me de noite/ o teu desejo" (HORTA, 1971, p. 86). De seguida, mostra-se a objetificação do sujeito poético, que diz que o homem tem "pressa de ter[es] o que só sente[s]", quer possuir dela "o que não sabe[s]" (HORTA, 1971, p. 87). Finalmente, é descrita a relação sexual involuntária, mostrando-se a condição de subjugação física, emocional e psicológica a que o sujeito poético está submetido: o corpo do homem desperta-a até que ela, saindo "do sono/onde resvala [resvalo]" (HORTA, 1971, p. 87), repila a noite. O desejo do homem encontra satisfação, indiferente ao facto de ter de ultrapassar uma não-vontade (a do ato sexual) e uma vontade (a de dormir). Mais: essa vontade tem de ser vergada, já que ele suspeita de que é usada para defender-se dele, não podendo a vontade feminina sobrepor-se à outra. É no ultrapassar da não-vontade que se mostra mais que a contraposição de vontades, que se mostra o domínio dele sobre dela como violação do desejo dela.

Por meio disto, Maria Teresa Horta traz para a poesia um novo sujeito poético, que nasce da tradição literária ao romper com ela, e assim rompe com a condição da subjugação das mulheres: a tradição literária, ao paralelizar-se com anos de dominação das mulheres, refletia o quadro de dominação que existia entre os sexos, já que compactuava com o silêncio, anulava sujeitos. Isto verificava-se ainda nas já referidas cantigas de amigo: parecendo trazer sujeitos novos para a poesia - as mulheres -, eram afinal escritas por homens, sendo estes, 
portanto, quem moldava, na sociedade e na tradição literária, as relações afetivas e sexuais. Os poemas que compõem Minha Senhora de Mim são, portanto, um ato político levado a cabo através da estética literária, já que clamam voz para quem a tem sonegada e um lugar social para quem pertence à sociedade. No caso, é a apropriação da linguagem que funciona como desafio ao instituído e, num contexto em que a ditadura salazarista afastava as mulheres do acesso à produção simbólica, ao invés de ser de somenos, é um ato político de relevo. Por estes motivos, poderia julgar-se, ao ler-se este livro, que é este um caso de poesia de resistência. Contudo, ao olhar-se para a apropriação da tradição literária e para a sua subversão, para o facto de esta ser trazida à produção simbólica através de uma mão feminina real, assim como a reclamação à sexualidade e a denúncia das opressões de género, ver-se-á que este é um caso de poesia de avanço. Afinal, a autora não se conforma nem se limita a resistir ao patriarcado, impedindo os seus avanços, confinando-se a uma bandeira num canto. Ao invés disto, desafia-o, ataca-o, e, ao fazê-lo, através do repto que lança, da provocação que erige, traz a ameaça da sua decomposição. A poesia que cria não é mera denúncia: em vez de limitar-se a evidenciar as desigualdades de géneros, subverte-as a recusa-as, reclama um lugar social para as mulheres, fá-lo no modo imperativo. Assim, Maria Teresa Hora não dá apenas voz à sexualidade das mulheres, antes as põe como centro da relação sexual. Neste ponto, será de notar o modo imperativo usado em tantos dos poemas, que também denotará a forma como a estética literária se põe ao serviço de uma visão política e social do mundo.

A autora afrontou abertamente a ditadura, tendo tido, claro, de enfrentar as consequências, das quais a tentativa de boicote à sua carreira literária por parte de Moreira Baptista é apenas um exemplo. É que, depois da publicação de Minha Senhora de Mim, a autora foi espancada na rua por três homens, tendo ainda recebido várias ameaças por via telefónica. Esta sucessão de episódios viria a servir-lhe, assim como a Maria Velho da Costa e a Maria Isabel Barreno, como mote para a escrita de Novas Cartas Portuguesas, que viria a transformar-se num dos grandes marcos das ações feministas no decorrer do Estado Novo, principalmente graças à onda de solidariedade de que auferiu a nível internacional. Graças à sua produção literária, à sua decisão pelo acesso à produção simbólica, Horta, como Maria Velho da Costa e Maria Isabel Barreno, enfrentou processos judiciais, não tendo acabado presa graças ao 25 de Abril de 1974. Como se vê pelo mote da obra a três, a perseguição do Estado Novo, e social, antes de demovê-la, estimulou-a. A autora usou a literatura como arma, pondo o poder simbólico no centro da luta política que levou a cabo.

Neste sentido, a autora usou a literatura não só para desafiar os cânones literários (se 
aos homens se destinava a produção simbólica, a eles se devia o cânone cultural), mas também para afrontar uma ordem social. A sua criação literária exige um lugar no mundo, destrói a ordem simbólica das estruturas da sociedade patriarcal, e, por isso, por criar um mundo possível em que a mulher é dona de si, procura a independência, não se sujeita à mão do homem, afronta o patriarcado e a moral do fascismo. Daí que Minha Senhora de Mim tenha escandalizado a sociedade da época e Novas Cartas Portuguesas tenha sido vilipendiada pelo regime.

\section{O processo de censura}

A ditadura teve um grande impacto na produção literária na medida em que foi matéria da criação literária de inúmeros escritores, ou seja, o zeitgeist de criação foi usado como matéria artística. Nesta produção literária, a perspetiva teve uma clara tendência para a crítica, assumindo grande parte dos escritores uma posição de confronto em relação à ideologia oficial, que, entre outras opressões, limitava a criação artística. Daí que a censura literária - necessária para que a ditadura soubesse durar (ROSAS, 2013) - desempenhasse ainda um papel fundamental na circulação dos livros, já que os censurava às centenas, entre literatura, manuais científicos e ciências sociais. Esta censura constante levou ao empobrecimento da criação literária, mas o pós-25 de Abril permitiu o resgate de várias das obras que a censura literária tentara apagar da vida pública, conseguindo-se uma memória literária da ditadura bem sedimentada.

A literatura, assim, vinculando mensagens de consciência do zeitgeist, era uma forma de poder simbólico, resistindo às imposições do zeitgeist, ainda que, várias vezes, os autores metaforizassem os seus textos, de forma a poderem iludir a máquina censória e levar a cabo as suas publicações.

Foi neste contexto que Minha Senhora de Mim, o nono livro que Maria Teresa Horta publicou, surgiu. A obra não usa o zeitgeist como matéria artística, mas, por aquilo a que previamente nos referimos, confronta-o, propõe um mundo em que este é alterado. À época da sua publicação, em 1971, a autora contava já com o olhar atento da PIDE. Aliás, na ficha da autora na polícia política, que se encontra na Torre do Tombo, pode encontrar-se um documento, que data do início de 1967, em que a Brigada da Secção Central responde a um pedido de informações sobre a autora:

\section{RELATÓRIO}

ASSUNTO: - Interessa obter a identidade completa de MARIA TERESA HORTA que consta ser escritora. Sugere-se a consulta à Conservatória da Propriedade 
Literária - Biblioteca Nacional de Lisboa. Número do Bilhete de Identidade se possível.

Trata-se de MARIA TERESA DE MASCARENHAS HORTA BARROS, casada, escritora, natural da freguesia de S. Sebastião da Pedreira, concelho de Lisboa, nascida a 20 de Maio de 1937, filha de Jorge Augusto da Silva horta e de Carlota Maria de Mascarenhas Horta, residente na Avenida Marconi, n16-5 Lisboa.

A MARIA TERESA é titular do Bilhete de Identidade número 1364329, emitido pelo Arquivo de Identificação de Lisboa, em 11/10/61.

Lisboa, 31 de Janeiro de 1967

BRIGADA DA SECÇÃO CENTRAL

Anos mais tarde, aquando da publicação de Minha Senhora de Mim, viria a confirmar-se esta atenção da PIDE. Publicada na colecção "Cadernos de Poesia", das Publicações Dom Quixote, dirigidas por Snu Abecassis, viria a ser de imediato apreendida sob a acusação "da moral tradicional da nação", numa classificação que serviria para deslegitimar, tanto literária como socialmente, a obra de Horta, ao mesmo tempo que se vivia sob uma noção muito limitada da moral: considerando a obra imoral e pornográfica, a classe dominante impunha a sua moral como moral natural, servindo os seus interesses de classe ao mesmo tempo que impunha a divisão sexual que queria como eixo estruturante da sociedade. Esta acusação de imoralidade seria ainda aquela que estaria a sustentar a apreensão e proibição de Novas Cartas Portuguesas (1972), que, note-se, foi escrita como resposta à recepção que Minha Senhora de Mim teve. Afinal, o escândalo fora tão grande, não só através da máquina censória do regime, mas também no que concerne à resposta social (Maria Teresa Horta foi espancada na rua e recebeu várias ameaças por telefone), que as autoras pensaram que, se a obra de uma mulher causava tanta agitação, a obra de três causaria muita mais.

Moreira Baptista, a que já aqui foi feita referência, comandou o processo de censura desta obra de Horta, indo além da mera proibição e mandando chamar Snu Abecassis para ameaçá-la com o encerramento da sua editora se voltasse a publicar algum texto da autora. Para além do seu papel enquanto censor literário, a quem cabia zelar pelos interesses do Estado Novo, nos quais se incluía a perpetuação da moral que impunha, motivava-o o boicote à carreira literária de Horta.

Uma vez proibida, Minha Senhora de Mim contou com vários autos de apreensão, estando alguns destes acessíveis na Torre do Tombo, no processo da autora. O auto do dia 14 de Junho de 1971, por exemplo, informa sobre a apreensão da obra numa livraria em Setúbal, referindo ainda a devolução de 75 exemplares e a venda de outros. Este auto é ainda acompanhado por uma nota que não só informa sobre uma apreensão ocorrida na Livraria 
Antecipação como informa da venda dos exemplares que estavam à venda na Livraria Nuno Álvares e na Galeria Coldex. No dia seguinte, foi escrita ainda uma nota com a mesma informação, ainda que haja um erro no título da obra, referida como Minha Mulher Minha.

Constata-se, assim, a proximidade com que a PIDE vigiava a criação literária de Maria Teresa Horta, tendo sido implacável na censura desta obra e tentando boicotar a sua carreira, independentemente dos outros boicotes que tivesse de fazer para isso (no caso, a editora de Snu Abecassis). O espancamento e as ameaças de que Maria Teresa Horta foi vítima reflecte ainda o quão transgressora aquela obra era naquele contexto. Afinal, não só se tinha apropriado de um papel social à partida vedado às mulheres como se havia ainda aventurado num tema proibido.

\section{Conclusões}

Minha Senhora de Mim traz para a literatura portuguesa um novo modelo de relações entre os sexos, contrastando com as políticas impostas pelo Estado Novo, constitucionalmente consagradas (ao rejeitar a subalternidade das mulheres), reclamando para as mulheres o direito ao prazer sexual e a um lugar na sociedade que não se limitasse ao de coadjuvante. Assim, a autora apresenta-se, primeiro, como agente social com acesso ao poder simbólico, e, segundo, mostra as mulheres enquanto agentes sociais em pleno direito. Desta forma, a obra de 1971 é já imbuída de uma nova formulação social, já que rejeita a moral limitada, limitante e totalitária imposta pelo regime português. O regime, pouco atreito a aceitar contradições, fez o que seria expectável, usando todos os mecanismos ao seu alcance para apagar a obra da vida pública e para intimidar a autora. Foi ainda mais longe e, após a proibição da obra, intimidou ainda quem o publicou, estreitando as possibilidades de a autora prosseguir uma carreira literária.

O discurso de Maria Teresa Horta, rompendo com as barreiras morais e sociais que o regime impunha, era libertador e incomodava o poder instituído, que teve, por isso, necessidade de vilipendiar a obra da autora, considerando que esta ofenderia a "moral tradicional da nação", de forma a que a autora fosse vista como herética. Ainda assim, por muito que a PIDE tenha usado todos os mecanismos ao seu alcance, do seu poder de definir o que podia circular à prossecução social, não foi bem sucedida nem no boicote à carreira da autora nem no apagamento desta obra em particular da vida pública. Se a primeira viria a ter uma longa vida literária pela frente, sendo hoje uma das escritoras cujo nome tem mais peso na literatura coetânea portuguesa, a segunda viria ainda a ser republicada em 1974, pela Editorial Futura, ou seja, logo após o término da ditadura, e várias décadas mais tarde, 
primeiro numa edição da Gótica, em 2001, e depois numa edição da LeYa/Dom Quixote, em 2015. Em 1990, Minha Senhora de Quê, de Ana Luísa Amaral, fora também publicada, dialogando intertextualmente com Minha Senhora de Mim. A prova última do insucesso da PIDE reside na inclusão da obra no Plano Nacional de Leitura (PNL), desde o ano lectivo de 2016/2017 , chegando às novas gerações de estudantes e leitores: é que, ocupando um lugar no sistema de ensino português, a obra não só mostra que sobreviveu à ditadura como garante o seu lugar no cânone. O facto de Maria Teresa Horta ter continuado a ter uma produção literária intensa, e de qualidade, aliada ao facto de ser uma das figuras mais proeminentes da cultura portuguesa, mostra-nos o insucesso da polícia política: a obra não só sobreviveu como se canonizou.

\section{Referências}

BARRENO, Maria Isabel; HORTA, Maria Teresa; COSTA, Maria Velho da. Novas Cartas Portuguesas. Alfragide: Dom Quixote, 2010.

BARRENO, Maria Isabel. Outros Legítimos Superiores. Porto: Publicações Europa-América, 1970.

BOURDIEU, Pierre. A dominação masculina. Rio de Janeiro: Bertrand, 2012.

COSTA, Maria Velho da. Maina Mendes. Lisboa: Moraes Editores, 1969.

HORTA, Maria Teresa. Ambas as Mãos Sobre o Corpo. Porto: Publicações Europa-América, 1970.

HORTA, Maria Teresa. Minha Senhora de Mim. Lisboa: Publicações Dom Quixote, 1971

NUNES, Maria Leonor. Maria Teresa Horta: Feminista não é pecado. (Entrevista com Maria Teresa Horta). Jornal de Letras, Artes e Idéias. Lisboa: 28/02 a 13/03/2007, p. 6-8, 2007.

OLIVEIRA, Ana Maria Domingues de. Quarenta anos de Minha Senhora de Mim. In: SEMINÁRIO NACIONAL MULHER E LITERATURA, 14. SEMINÁRIO INTERNACIONAL MULHER E LITERATURA, 5. 2009. Anais... Natal: Idéia, 2009, p. 4-5 paginação inicial e final da parte referenciada. Disponível em: $<$ http://www.telunb.com.br/mulhereliteratura/anais/wpcontent/uploads/2012/01/ana_maria_domingues.pdf.>. Acesso em: 19/09/2016.

ROSAS, Fernando. Salazar e o Poder. A Arte de Saber Durar. Lisboa: Tinta-da-china, 2013.

\section{Arquivos da Torre do Tombo consultados}

Maria Teresa Horta, Proc - 339 - CI (2), NT6994

Processo $n^{0} 339-\mathrm{CI}(2)$

${ }^{4}$ A obra Poemas para Leonor também está integrada no PNL, com recomendação para o Ensino Secundário. 
$\mathrm{PT} / \mathrm{TT}-\mathrm{AC}-\mathrm{PIDE} / \mathrm{DGS}-\mathrm{SC}-\mathrm{Bol}-639960-8412$

PT/TT - AC - PIDE/DGS -SC - SR - 2702/60 - 3036

$\mathrm{PT} / \mathrm{TT}-\mathrm{AC}-\mathrm{PIDE} / \mathrm{DGS}-\mathrm{SC}-\mathrm{CI}(2)-339-6994$

PT/TT - AC - PIDE/DGS -E/GT - 4213 - 1503

Not only resisting, but also advancing: from the boycott of Minha Senhora de Mim to its canonization

Abstract: In this article, we will analyze how Minha Senhora de Mim (1971), by Maria Teresa Horta, confronted the dictatorship that was its zeitgeist, starting from the way she used canonical literature and literary traditional to challenge a specific status quo, bringing a new model of relationships between sexes to literature, contrasting with the politics Estado Novo was imposing, that were constitutionally safeguarded, claiming to women the right both to sexual pleasure and to a place in society that was not limited to being adjunctive. The way literary traditional was challenged will get some attention, since it is done through the subversion of the content of medieval cantigas de amigo. In a second part, we will analyze not only the context of the literary work creation, but also the consequent action of PIDE. Finally, we will analyze the role of the political policy as far as the boycott of this book and the literary career of the author are concerned, trying to understand if it was successful, as well as the role this work plays in the Portuguese literary canon.

Keywords: Maria Teresa Horta. Poetry. Dictatorship. Censorship. Canon.

Recebido: 11/11/2016

Aceito: 05/05/2017

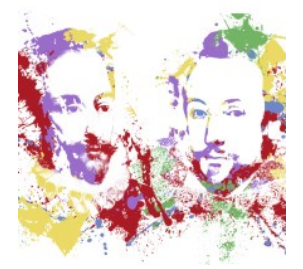

